\title{
Avaliação do modelo nacional de interoperabilidade do Poder Judiciário brasileiro
}

\section{Evaluation of national interoperability model of the judiciary}

\author{
Egon Sewald Jr* \\ Lucas Silveira \\ Aires José Rover ${ }^{* * *}$
}

\section{Resumo}

A Lei 11.419/2006 possibilita a virtualização dos processos judiciais, permitindo celeridade processual. Para que os benefícios possam ser efetivos, é necessária uma interligação entre os atores envolvidos no curso do processo. O Modelo Nacional de Interoperabilidade, definido pelo Conselho Nacional de Justiça como padrão de comunicação, tem como objetivo possibilitar essa interação. O presente artigo pretende observar, na literatura, os benefícios do processo eletrônico e sua relação com o Modelo Nacional de Interoperabilidade, além de fornecer avaliação, aplicando framework de valoração de padrões de interoperabilidade governamental, verificando sua conformidade com os requisitos apresentados pela literatura. Através de pesquisa bibliográfica, foram comprovadas as hipóteses relacionadas aos benefícios do processo eletrônico e da aplicação do Modelo Nacional de Interoperabilidade. Apesar de tratar-se de uma iniciativa com bons resultados na diminuição de tempo, este estudo aponta críticas que podem ser interpretadas como sugestões.

Mestre em Engenharia e Gestão de Conhecimento da Universidade Federal de Santa Catarina (2012). Doutorando no Departamento de Engenharia e Gestão de Conhecimento da Universidade Federal de Santa Catarina, onde pesquisa Governo Eletrônico, Inclusão Digital e Sociedade do Conhecimento. Florianópolis - Santa Catarina - Brasil. E-mail: egonsj@gmail.com

* Mestre em Ciência da Computação pelo Programa de Pós-Graduação da Universidade Federal de Santa Catarina - UFSC. Atualmente é professor do Instituto Federal de Santa Catarina - IFSC. Florianópolis - Santa Catarina - Brasil. E-mail:Iucassilveiraufsc@gmail.com

*** Doutor em Direito pela Universidade Federal de Santa Catarina. Atualmente é prof. associado da UFSC nos cursos de direito e engenharia e gestão do conhecimento. Florianópolis - Santa Catarina - Brasil. E-mail: aires.rover@gmail.com 
Palavras-chave: Processo eletrônico. Interoperabilidade. Modelo Nacional de Interoperabilidade. Poder Judiciário.

\section{Abstract}

The Brazilian Law 11.419 / 2006 allows the virtualization of legal proceedings, enabling procedural celerity. So that the benefits can be effective, it is necessary interconnection between the actors involved in the course of the process. The National Interoperability Model is defined by the National Council of Justice as communication standard and aims to facilitate the interaction between the stakeholders. This article aims to verify, in the literature, the benefits of electronic process and its relationship with the National Interoperability Model. Also it provides assessment using the valuation framework of government interoperability standards, verifying its compliance with the requirements presented by literature. Through literature review, the hypotheses related to the benefits of the electronic process and the implementation of the National Interoperability Model promoting interaction between the stakeholders in the electronic process were proven, and that the application of interoperability empowers its benefits. Despite that this is an initiative with good results in decrease the time, when the settings of National Interoperability Model are confronted with government standards requirements, its complies with some criteria and those that do not observed, this study points through criticism, which can be interpreted as suggestions.

Keywords: Electronic process. Interoperability. National interoperability model. Judiciary.

\section{Introdução}

A tramitação célere do processo é um direito garantido pela Constituição Federal àqueles que demandam da administração pública - e, em casos de processos judiciais, do Poder Judiciário. Com a observação de métodos, ferramentas e técnicas aplicados no competitivo ambiente corporativo e a constatação de defasagem quanto aos aplicados nos órgãos governamentais, a preocupação com princípios de eficiência e eficácia propõe a utilização destes para a melhor prestação de serviços públicos, incluindo a atividade judicante. 
A legislação brasileira, através da Lei 11.419/2006, possibilita a virtualização dos processos judiciais, tendo como objetivo, com a sua desmaterialização, quebrar as barreiras físicas, diminuir o tempo morto para tarefas inerentes à montagem da pasta do processo, facilitar a comunicação entre as partes e o poder judicante, desempenhando, dessa forma, papel fundamental para a celeridade processual.

Para que os benefícios possam ser efetivos, é necessária uma interligação entre os atores envolvidos no curso do processo, de forma que possam realizar as operações inerentes aos seus papéis no trâmite, sem a carga física e, consequentemente, o tempo de trânsito e cargas.

O Modelo Nacional de Interoperabilidade, definido pelo Conselho Nacional de Justiça como padrão de comunicação, tem como objetivo normatizar essa interação. O estabelecimento de padrões a qualquer ator envolvido é aberto à possibilidade de envio de peças judiciais e interação com o processo, com funções semelhantes àquelas encontradas nas interações físicas, porém, com maiores facilidades.

Através de revisão de literatura, este artigo tem como objetivo observar os benefícios do processo eletrônico judicial, as definições para a interação dos atores e utilização do Modelo Nacional de Interoperabilidade, seus benefícios junto ao processo eletrônico, bem como requisitos para padrões de interoperabilidade. Ainda, aplicar avaliação desses requisitos, por meio de framework de valoração de padrões de interoperabilidade governamental, verificando sua conformidade com os requisitos apresentados pela literatura.

\section{Metodologia}

Para o desenvolvimento deste trabalho, em um primeiro instante, a opção por iniciar com uma pesquisa bibliográfica com abordagem quantitativa prevaleceu. A seleção de termos de pesquisa tem como objetivo responder, inicialmente, a confirmação das hipóteses:

$\underline{\mathrm{H} 1 \text { - Processo eletrônico gera benefícios para prestação }}$ jurisdicional. 
$\underline{H} 2$ - Existe interação entre o processo judicial eletrônico e a interoperabilidade no Judiciário, confirmando a aplicação de Modelo Nacional de Interoperabilidade como framework de interoperabilidade do Judiciário.

H3 - A interoperabilidade, da maneira que é utilizada, potencializa os benefícios do processo eletrônico.

No caso de alguma dessas hipóteses não ser confirmada, o estudo deve ser encerrado. Caso contrário, é iniciada uma segunda fase de pesquisa bibliográfica, de modo a levantar, com base na literatura, um modelo de avaliação de interoperabilidade.

Em uma terceira fase para o estudo, o modelo de avaliação escolhido - ou a combinação de modelos de avaliação, bem como sua adaptação à realidade do judiciário brasileiro - é aplicado, de modo a estabelecer uma avaliação do framework de interoperabilidade e modelos escolhidos pelos órgãos competentes.

Trata-se, também, de uma pesquisa de ação, pois envolveu a participação efetiva do pesquisador e ação por parte das pessoas envolvidas no problema de pesquisa (SOUZA; FIALHO, 2007). Por sua vez, aplica-se a busca de uma visão sistêmica do mundo. Quanto ao método, podemos afirmar que a terceira fase trata-se de uma pesquisa qualitativa, visto que contempla o conjunto de características capazes de identificá-la como tal, as quais são, segundo Godoy (1995, p. 62):

1. o ambiente natural como fonte direta de dados e o pesquisador como instrumento fundamental;

2. o caráter descritivo;

3. o significado que as pessoas dão às coisas e à sua vida como preocupação do investigador;

4. o enfoque indutivo.

Neves (1996) completa que, nas pesquisas qualitativas, frequentemente o pesquisador busca entendimento dos fenômenos sob a perspectiva dos participantes da situação estudada. 
Por sua vez, Downey e Ireland (1979) apontam que os métodos qualitativos beneficiam e enriquecem as avaliações de características de ambientes organizacionais. O objeto deste trabalho refere-se a ambientes interorganizacionais que utilizam os métodos computacionais para interação entre os atores.

A partir dessa definição, os autores se propõem a buscar entendimento, utilizando-se de pesquisa documental, com o objetivo de confirmar ou refutar a seguinte hipótese:

H4 - O Modelo Nacional de Interoperabilidade contempla os requisitos definidos pela literatura, em caso de avaliação segundo critérios por ela definidos.

O presente trabalho classifica-se, portanto, como uma pesquisa empírica, utilizando de métodos qualitativos.

\section{Revisão de Literatura}

De modo a estabelecer um entendimento inicial e dos conceitos necessários para confirmação das hipóteses $\mathrm{H} 1, \mathrm{H} 2$ e $\mathrm{H} 3$, faz-se necessária uma revisão de literatura. Foram levantados conceitos de nova administração pública, processo judicial eletrônico, interoperabilidade, benefícios do processo digital e potencialidades quanto ao incremento de benefícios do processo eletrônico, com uso de interoperabilidade.

\subsection{Nova Administração Pública e Poder Judiciário}

O papel da administração pública, em qualquer esfera ou poder, é executar serviços aos cidadãos, oferecendo a estes o cumprimento de seus direitos fundamentais. Silva et al. (2008) afirmam que a inclusão de novas tecnologias tende a promover ganhos de eficiência nas atividades e serviços prestados pelo Estado, e Rifkin (2005) afirma que a intensificação da introdução de novas e sofisticadas tecnologias de informação e comunicação e das novas técnicas de gestão permitem uma elevação constante da produtividade. 
A nova administração pública é, antes de mais nada, um conceito que busca dar conta das transformações por que vêm passando os governos ao redor do mundo, tendo em vista a revolução tecnológica e o impacto da adoção, pelo setor público, de técnicas gerenciais testadas e aprovadas no ambiente empresarial. (APRESENTAÇÃO, 2014)).

A utilização de ferramentas de tecnologia de informação e comunicação objetivando melhor prestação de serviços ao cidadão é conhecida como "governo eletrônico. Segundo Rover (2009, p. 21), o governo eletrônico pode ser conceituado como:

uma forma puramente instrumental de administração das funções do Estado [...] e de realização dos fins estabelecidos ao Estado Democrático de Direito que utiliza as novas tecnologias da informação e comunicação como instrumento de interação com os cidadãos e de prestação de serviços públicos.

Segundo Ribeiro (2000), no tocante ao posicionamento do Judiciário como poder político do Estado, o que se espera, no Brasil, é a manutenção das mesmas regras e princípios hoje existentes, que igualam ou até mesmo superam em conquistas as já obtidas por outros importantes Estados Democráticos de Direito. O problema está em colocar em prática esses princípios, de maneira a tornar o exercício das funções jurisdicionais menos moroso e mais eficiente, tendo em conta que o Judiciário presta serviço público de alta relevância, qual seja, distribuir justiça.

A efetividade, entendida como princípio a ser seguido pelo Judiciário, traduz-se como o impacto trazido pelo resultado obtido por suas decisões. Difere da eficácia, pois esta apenas indica se o objetivo programado foi atingido, enquanto aquela se preocupa em apontar se houve uma melhora na prestação do serviço, sendo traduzida pelo impacto causado pela ação adotada. Efetividade é a soma da eficiência e da eficácia ao longo do tempo (ARAÚJO, 2004 apud SILVA, 2005). 
Com objetivo de fiscalizar a prestação de serviços realizados pelo Judiciário, foi criado o Conselho Nacional de Justiça (CNJ). O CNJ é uma instituição pública que visa aperfeiçoar e regulamentar o trabalho do sistema judiciário brasileiro, principalmente no que diz respeito ao controle e à transparência administrativa e processual. Criado em 31 de dezembro de 2004 e instalado em 14 de junho de 2005, o Conselho tem sua sede em Brasília, mas atua em todo o território nacional regulamentando os 91 Tribunais de Justiça do país e estabelecendo metas voltadas ao acompanhamento de ações (BRASIL. CNJ, 2009).

Uma das insistentes metas do CNJ nos últimos anos é a agilidade e eficiência da Justiça, principalmente no que diz respeito ao julgamento de processos, tornando acessíveis as informações processuais nos portais da rede mundial de computadores (internet), com andamento atualizado e conteúdo das decisões de todos os processos (respeitado o segredo de justiça), objetivando a celeridade processual.

Como grande avanço apontado, tanto pela comunidade acadêmica como pela comunidade jurídica, tem-se o processo judicial eletrônico, que obtém, através da informatização de um conjunto mínimo e significativo de ações do processo judicial, maior celeridade e produtividade, principalmente na execução de tarefas mais rotineiras e repetitivas, com a eliminação do chamado tempo morto do processo (ROVER, 2008).

Com o uso da internet, existe a possibilidade de oferta de serviços aos cidadãos, às empresas e a outros órgãos da administração pública. Inclui-se, nesse conjunto de serviços, a possibilidade de interoperar e integrar sistemas de informação.

Uma das iniciativas do CNJ, visando melhorar a transferência de comunicações e documentos referentes a processos judiciais eletrônicos, é o Modelo Nacional de Interoperabilidade, definido pelas equipes técnicas dos órgãos (STF - CNJ - STJ - CJF - TST - CSJT AGU e PGR) de acordo com as metas do termo de cooperação técnica $n^{\circ} 58 / 2009$, visando estabelecer os padrões para intercâmbio de informações de processos judiciais e assemelhados entre os diversos 
órgãos de administração de justiça, além de servir de base para implementação das funcionalidades pertinentes no âmbito do sistema processual (BRASIL. CNJ, 2009)

Observa-se, porém, uma lacuna com a falta de estudos acadêmicos que relacionam o Modelo Nacional de Interoperabilidade e o conceito de interoperabilidade, considerando os conceitos encontrados na literatura, bem como o atendimento dos critérios estabelecidos por modelos de avaliação.

\subsection{Processo judicial digital}

A partir da Lei 11.419, de 19 de dezembro de 2006, que dispõe sobre a informatização do processo judicial, foi instituído o marco regulatório do Brasil quanto ao uso de meios eletrônicos na tramitação de processos, na comunicação de atos e transmissão de peças em todos os graus de jurisdição nos processos civil, penal e trabalhista.

Um processo judicial é a materialização de uma demanda, de um cidadão ou organização, quando há litígio sobre algum assunto, visto que o Poder Judiciário tem papel fundamental para garantir os objetivos fundamentais da República: construir uma sociedade livre, justa e solidária; garantir o desenvolvimento nacional; erradicar a pobreza e a marginalização reduzindo as desigualdades sociais e regionais; e promover o bem de todos, sem preconceitos de origem, raça, sexo, cor, idade e quaisquer outras formas de discriminação (RIBEIRO, 2000).

Com o avanço das ferramentas de tecnologia de informações e sua aplicação junto ao Judiciário, regulamentada e aceita com a Lei 11.419/2006, o processo judicial digital foi legitimado, gerando condições para a prestação de serviços jurisdicionais de maneira mais célere, com custos menores e a eliminação do papel.

Segundo Rover (2008), o processo digital é resultado da informatização de um conjunto mínimo e significativo de ações e, por consequência, de documentos organizados e ordenados em uma sequencia definida de fluxos de trabalho - representando fases 
processuais, atendendo a requisitos de autenticidade, temporalidade e integridade, com a eliminação do uso do papel.

A partir dessa definição, pode-se afirmar que o processo judicial digital é fruto de avanços legislativos, jurídicos, tecnológicos, de gestão e governo eletrônico, e, acima de tudo, da conscientização da sociedade e dos operadores do Direito da necessidade de prestação jurisdicional com maior qualidade e celeridade (ROTTA et al., 2013). Para que o processo judicial digital seja realmente factível, segundo o estudo de Krammes (2008), sistemas informatizados especializados se fazem necessários, visando criar as condições necessárias para a automatização das rotinas de trabalho, objetivando a virtualização dos processos judiciais.

Tal situação não é somente desejável, mas necessária, pois, de acordo com Rotta, Rover e Silva (2011), a análise das metas de 2010 e 2011 do Conselho Nacional de Justiça demonstram o foco no incremento da produtividade e a celeridade no julgamento das lides por parte dos Tribunais de Justiça, além da redução do tempo de tramitação de processos.

O CNJ, por meio da Resolução n 90 , de 29 de setembro de 2009, determinou o uso de sistemas de gestão de processos judiciais digital, e a virtualização de parcela significativa dos processos em tramitação nos Tribunais.

O uso de sistemas informatizados especializados pode resultar em celeridade e produtividade, principalmente na execução de tarefas mais rotineiras e repetitivas, com a eliminação do chamado tempo morto do processo, o qual é conceituado por Olivieri (2010) como sendo "aquele em que o processo está em andamento, sem que estejam ocorrendo atos processuais que efetivamente levem ao fim do processo".

Aproximadamente dois terços do tempo total de tramitação das ações de rito ordinário dos processos judiciais brasileiros são consumidos com o chamado tempo morto do processo, o qual é a totalização dos períodos de tempo destinados a juntadas (petições e 
documentos em papel), carimbos, encadernamentos, vistas a partes/ advogados, membros do Ministério Público, movimentações físicas com idas e vindas a gabinetes, escritórios e residências de juízes, promotores de justiça, advogados, procuradores e defensores (BOTELHO, 2007). Podemos observar, portanto, que o esforço demandado pela burocracia gerada para manutenção e gestão de processos físicos atingiu níveis críticos para os parâmetros mínimos de eficiência da atuação estatal, constituindo-se um pesado ônus para a eficiência do serviço de prestação jurisdicional.

\subsection{Benefícios oriundos do processo judicial digital}

Para Rotta, Rover e Silva (2011), os impactos proporcionados pelas inovações tecnológicas (relacionadas ao processo judicial digital) no trabalho dos operadores do Direito são de considerável extensão. A digitalização de arquivos, legislações e jurisprudências, em conjunto com ferramentas de busca e facilidade de acesso pela internet, facilita e torna ágil uma das principais etapas do trabalho jurídico, a pesquisa. A facilidade de armazenamento e recuperação de documentos resulta em economia de tempo na fase preparatória dos pareceres, decisões e teses, permitindo aos operadores do Direito dedicar tempo e atenção às atividades de maior valor agregado (como as fases de análise jurídica e elaboração de teses), aumentando muito a produtividade desses profissionais, além da ampla redução de custos de todo o processo.

Os benefícios do uso da tecnologia no trabalho dos operadores do Direito estão em conformidade com Hinings (1995): diminuem o volume do esforço e dos custos necessários, bem como o tempo para a execução de atividades importantes, porém, rotineiras (como a pesquisas em bases de dados de legislações e jurisprudências).

A partir de uma revisão bibliográfica considerando diversos autores, como Botelho (2007), Leal (2006), Leal (2009), Lima (2003), Maciel (2000), Madalena (2007), Madalena (2012), Krammes (2008), Rover (2008), Silva (2010), é possível identificar e destacar mais benefícios propiciados pelo processo judicial digital, como: 1. independência de 
localização geográfica do processo judicial digital; 2. acesso remoto do processo aos operadores do Direito; 3. segurança digital, com a utilização de certificação e assinatura digital; 4. eliminação do papel; 5. realização de correições virtuais, que passam a ser realizadas na própria Corregedoria de Justiça.

De acordo com Botelho (2007), Madalena (2007), Krammes (2008), Rover (2008), Rotta, Rover e Silva (2011) e Silva (2010), a Lei 11.419 introduziu significativas alterações no funcionamento da Justiça e viabilizou muitas mudanças nas rotinas de trabalho para a adoção do processo judicial digital, como: 1. rompimento com a estruturação do processo tradicional; 2. os atos processuais passaram a ser praticados diretamente no sistema pelos operadores do Direito, mediante a assinatura digital, baseada em certificado digital emitido por uma autoridade certificadora credenciada; 3 . interação entre todos os operadores do direito por meio do sistema; 4. a juntada de documentos e expedição de certidões é automatizada, eliminando a burocracia; 5. possibilidade de consulta e controle, em tempo real e de maneira remota, do andamento dos processos pelas partes e operadores do Direito; 6. celeridade na distribuição, tramitação e julgamento de todo tipo de processo ou recurso, pois os atos processuais são realizados de forma totalmente eletrônica; 7. acesso instantâneo aos dados e autos processuais; e 8. publicação de atos no Diário da Justiça Eletrônico.

Assim, observa-se uma quebra de paradigmas em relação ao processo judicial em papel, e essa quebra possibilita algumas vantagens produtivas. Conforme Madalena (2007), o valor do processo judicial digital reside na obtenção de vantagem produtiva, com a eliminação de tarefas atribuídas aos operadores do Direito (juízes, promotores, advogados e serventuários da Justiça). A maior parte do serviço de prestação jurisdicional deve ser substituída pela informatização automatizada, de modo a promover a celeridade dos julgamentos judiciais. Tal assertiva é corroborada por Silva (2010), ao considerar o processo judicial digital a solução para a morosidade, uma vez que esta é a antítese da justiça. Ainda nesse sentido, o relatório "Justiça em Números 2014", do CNJ (referente a dados de 2013), apresenta 
avanços quanto ao descongestionamento, mas apresenta ainda a morosidade como risco indesejável, podendo resultar em menor procura dos serviços judiciários, por descrença.

O relatório aproxima a lente sobre o funcionamento do Judiciário, constatando intensa movimentação processual nas varas e tribunais. A Justiça brasileira apresenta um alto índice de congestionamento - mais de $70 \%$ na Justiça Estadual, com cerca de 60,1 milhões de processos esperando julgamento. Tais dados demonstram o alto custo do Judiciário para o país, com seus reflexos sociais negativos, responsáveis por minar a confiança dos jurisdicionados, afastar investimentos e empresas estrangeiras e retrair o mercado, afetando toda a economia.

Esses números evidenciam o crescimento de litigiosidade pelo qual passa o país, de modo que o aumento da carga processual e a dificuldade em julgar com celeridade os processos embaraçam a prestação de serviços jurisdicionais com qualidade e eficiência.

Além da diminuição de tempo morto, a possibilidade de integração entre os sistemas de informação dos atores envolvidos pode diminuir drasticamente o tempo para dar conhecimento às partes das ações do Judiciário e movimentações do processo. Com essa motivação, observamos o Modelo Nacional de Interoperabilidade.

Dessa forma, observa-se como principal benefício do processo judicial digital uma diminuição do tempo de tramitação do processo judicial. Avaliando o resultado parcial da pesquisa, a hipótese "H1 Processo Eletrônico gera benefícios para prestação jurisdicional” é, portanto, confirmada.

\subsection{Interoperabilidade}

A interoperabilidade é a característica que se confere aos sistemas de informação de trabalhar em conjunto, promovendo uma integração. A Organização Internacional de Normalização (ISO) a define como a capacidade de comunicar, executar programas ou transferir dados entre várias unidades funcionais, não exigindo que o usuário tenha muito ou 
algum conhecimento das características únicas de tais unidades (ISO 1993).

O Portal "Governo Eletrônico" apresenta este conceito de interoperabilidade:

A interoperabilidade pode ser entendida como uma característica que se refere à capacidade de diversos sistemas e organizações trabalharem em conjunto (interoperar) de modo a garantir que pessoas, organizações e sistemas computacionais interajam para trocar informações de maneira eficaz e eficiente. (GOVERNO ELETRÔNICO, 2003).

Também podemos observar o conceito do portal Software Público (201-):

Interoperabilidade é a capacidade de dois ou mais sistemas (computadores, meios de comunicação, redes, software e outros componentes de tecnologia da informação) de interagir e de intercambiar dados de acordo com um método definido, de forma a obter os resultados esperados.

Quanto ao uso da interoperabilidade em sistemas de informação governamentais, há um grande número de possibilidades de troca e compartilhamento de informações entre órgãos, ou mesmo disponibilização de dados públicos. Flak et al. (2009) apontam que interoperabilidade é um aspecto fundamental de tal prestação de serviços integrados. Essa afirmação é completada por Lallana (2008), para quem a interoperabilidade de sistemas permite ao governo o fornecimento de um serviço melhor, ajudando em uma melhor tomada de decisão e uma melhor governação.

Com base nessas definições, observamos a importância da interoperabilidade no ambiente governamental, considerando que ela não é somente a integração de sistemas ou redes, ou seja, não contempla simplesmente uma definição de tecnologia, mas deve considerar, também, as interações organizacionais e os acordos semânticos. 


\subsection{Padrão de Interoperabilidade de Governo Eletrônico Brasileiro}

O governo brasileiro define uma série de requisitos em um padrão de interoperabilidade. Segundo definição do portal Governo Eletrônico,

arquitetura ePING - Padrões de Interoperabilidade de Governo Eletrônico - define um conjunto mínimo de premissas, políticas e especificações técnicas que regulamentam a utilização da Tecnologia de Informação e Comunicação (TIC) no governo federal, estabelecendo as condições de interação com os demais Poderes e esferas de governo e com a sociedade em geral. (GOVERNO ELETRÔNICO, 2003).

O padrão não é imposto aos cidadãos, mas o governo estabelece diretrizes e padrões aceitos pelo mercado e definidos para serem utilizados por quem, voluntariamente, desejar interoperar com o governo brasileiro.

Sua adoção se tornou obrigatória por órgãos do governo federal, segundo Portaria SLTI/MP n 5 , de 14 de julho de 2005, sendo facultativa aos poderes legislativos e judiciários. As preocupações do e-PING estão segmentadas em:

- interconexão: refere-se às tecnologias de conexão lógica e física; estabelece padrões para mensagem eletrônica, e-mail e das camadas enlace e físico, bem como o uso de VPN;

- segurança: definições de forma a reduzir riscos e garantir a integridade, confidencialidade, disponibilidade e autenticidade, observando-se as normas do governo federal referentes à Política de Segurança da Informação e Comunicações;

- meios de acesso: refere-se a padrões de como os serviços e informações podem ser acessados por cidadãos, organizações privadas ou governamentais de outras esferas, sejam por meios de dados abertos ou componentes de acesso utilizando telefonia móvel e TV digital; 
- organização e intercâmbio de informações: define políticas de organização e intercâmbio de informações, como uso de documentos de marcação XML e vocabulários de ontologias (e-VOG);

- áreas de integração para governo eletrônico: define formas de acessar os serviços para integração, como o uso de tecnologia WebService.

Na versão 2014, o e-Ping estabelece preocupações pertinentes com a interoperabilidade semântica (uso de ontologias), a promoção de discussões entre atores envolvidos para a definição de novos padrões, o estabelecimento de planejamento de aderência e adequação dos modelos e a migração para modelo orientado a serviços (SOA) (DOCUMENTO DE REFERÊNCIA DA E-PING, 2014).

Apesar de os autores considerarem o fato de não obrigatoriedade ao Poder Judiciário, a forma de gestão de padrões e aplicação de grupos de trabalho com a participação de organizações e profissionais da academia e mercado promove uma definição de padrões, tanto tecnológicos quanto organizacionais e semânticos, que podem ser aplicados em todos os poderes.

\subsection{Modelo nacional de interoperabilidade}

O Modelo Nacional de Interoperabilidade (MNI) foi criado com o intuito de proporcionar o intercâmbio de informações de processos judiciais e assemelhados entre tribunais e os diversos órgãos de administração da justiça no país. Além disso, também serve de base para a implementação das funcionalidades vinculadas aos sistemas processuais (MODELO DE INTEROPERABILIDADE DE DADOS DO PODER JUDICIÁRIO, 2014).

O MNI definido pelas equipes técnicas dos órgãos - STF (Supremo Tribunal Federal), CNJ (Conselho Nacional de Justiça), STJ (Superior Tribunal de Justiça), CJF (Conselho da Justiça Federal), TST (Tribunal Superior do Trabalho), CSJT (Conselho Superior da Justiça do 
Trabalho), AGU (Advocacia Geral da União) e PGR (Procuradoria Geral da República) -, conforme as metas do Termo de Cooperação Técnica ${ }^{\circ}$ $58 / 2009$, visa estabelecer os padrões para intercâmbio de informações de processos judiciais e assemelhados entre os diversos órgãos de administração de justiça, além de servir de base para implementação das funcionalidades pertinentes ao âmbito do sistema processual. Assim, a padronização de requisitos de interoperabilidade e o próprio processo judicial digital efetivamente contribuem para a integração do Poder Judiciário aos sistemas informatizados de outras instituições e o aumento da eficiência e eficácia na prestação jurisdicional.

Conforme definido no Modelo de Interoperabilidade de Dados do Poder Judiciário (2014), o MNI é composto por dois arquivos escritos no formato XML Schema Document (xsd). Esses esquemas definem e descrevem um grupo de objetos que devem ser utilizados pelos sistemas de informação de cada órgão, permitindo a intercomunicação dos sistemas, independentemente de implementação.

- intercomunicacao-2.2.2.xsd: Responsável por definir os objetos básicos do modelo para troca de informações processuais. Entre esses objetos, constam: dados de cabeçalhos, movimentações, assuntos, classes, polos processuais, partes do processo, documentos, tipos de documentos, entre outros. O objetivo deste esquema é permitir a utilização desses tipos básicos de objetos pelos serviços disponibilizados externamente. Além disso, há um elemento raiz, chamado intercomunicação, que possibilita encapsular quaisquer desses tipos em um único elemento.

- tipos-servico-intercomunicacao-2.2.2.xsd: Responsável por definir os tipos de elementos utilizados nas operações dos serviços WEB definidos neste modelo. Esse esquema encapsula os elementos do intercomunicacao-2.1.xsd, e mais alguns outros necessários para realizar as operações disponibilizadas pelos serviços WEB. 
A partir dos elementos descritos no esquema tipos-servicointercomunicacao-2.1.xsd, foi definido um documento WSDL, com a intenção de criar um modelo de serviço de comunicação ofertado por um tribunal. A Tabela 1 mostra os serviços disponíveis com uso da versão 2.2.2 do Modelo Nacional de Interoperabilidade.

\section{Quadro 1 Visão Geral das Operações}

\begin{tabular}{|l|l|l|}
\hline Seq & Nome & Parâmetros \\
\hline 1 & consultarAvisosPendentes & $\begin{array}{l}\rightarrow \text { consultarAvisosPendentes } \\
\leftarrow \text { consultarAvisosPendentesResposta }\end{array}$ \\
\hline 2 & consultarTeorComunicacao & $\begin{array}{l}\rightarrow \text { consultarTeorComunicacao } \\
\leftarrow \text { consultarTeorComunicacaoResposta }\end{array}$ \\
\hline 3 & consultarProcesso & $\begin{array}{l}\rightarrow \text { consultarProcesso } \\
\leftarrow \text { consultarProcessoResponse }\end{array}$ \\
\hline 5 & entregarManifestacaoProcessual & $\begin{array}{l}\rightarrow \text { entregarManifestacaoProcessual } \\
\leftarrow \text { entregarManifestacaoProcessualResposta }\end{array}$ \\
\hline 6 & confultarAlteracao & $\begin{array}{l}\rightarrow \text { consultarAlteracao } \\
\leftarrow \text { consultarAlteracaoResposta }\end{array}$ \\
\hline
\end{tabular}

Fonte: Modelo de Interoperabilidade de Dados do Poder Judiciário (2014, p.11).

Observada a existência do Modelo Nacional de Interoperabilidade e que sua definição contempla os requisitos de interoperabilidade, podemos confirmar a hipótese "H2 - Existe interação entre o processo judicial eletrônico e a interoperabilidade no judiciário, confirmando a aplicação de Modelo Nacional de Interoperabilidade como framework de interoperabilidade do judiciário". Não foi encontrada, porém, bibliografia que aborde benefícios encontrados com a implantação do MNI.

\subsection{Processo eletrônico e integração entre atores}

Apesar da ausência de bibliografia que aponte os benefícios da utilização do Modelo Nacional de Interoperabilidade, observa-se que a inexistência de papéis e a ruptura da estruturação tradicional permitem que a comunicação e o intercâmbio de dados ou documentos realizemse também eletronicamente, sendo utilizado por alguns tribunais, com modelos próprios de integração e interoperabilidade. Dessa forma, a diminuição de custos de transporte de documentos e, sobretudo, a diminuição de tempo para tal intercâmbio são facilmente percebidas. 
Rotta et al. (2013) apontam caso de intercâmbio de documentos de petições iniciais entre o sistema de informação da ProcuradoriaGeral Municipal de Florianópolis - órgão responsável por representar o município de Florianópolis em questões judiciais - e o Tribunal de Justiça de Santa Catarina, referentes à execução fiscal judicial quando o agente público efetua a cobrança de dívidas judicialmente, referente a impostos ou taxas devidas e não pagas. Neste estudo, os documentos são enviados através de serviço web (WebServices padrão WSDL), respeitando definições do Tribunal de Justiça de Santa Catarina (tais definições ocorreram antes de qualquer padrão existir), devendo ser assinados digitalmente e conter informações suficientes para sua judicialização - equivalentes àquelas se fosse realizada a petição inicial em papel. Apontam, em seu estudo, os principais ganhos referentes ao ano de 2012:

a) segundo dados históricos da Prefeitura de Florianópolis e do TJSC, um processo de cobrança em papel tem um custo entre $R \$ 530,00$ a $R \$ 700,00$ para a PMF. Em meio eletrônico, esse custo cai para valores em torno de $R \$$ 3,00 ;

b) a dívida estimada a ser cobrada pela PMF para ajuizamentos eletrônicos é de aproximadamente

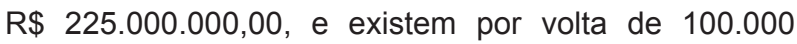
processos de execução fiscal tramitando em meio eletrônico, representando mais de 280.000 Certidões de Dívidas Ativas ajuizadas (que geraram processos judiciais);

c) o Município de Florianópolis irá gastar $R \$ 300.000,00$ (100.000 processos $\times \mathrm{R} \$ 3,00$ por processo) para cobrar a dívida de $\mathrm{R} \$ 225.000 .000,00$. Se estes processos tramitassem em meio físico, o custo da cobrança aumentaria para $\mathrm{R} \$ 5,3$ milhões $(100.000 \times \mathrm{R} \$ 530,00)$;

d) com a integração com os Correios e adoção do AR Digital, ocorreu um ganho significativo no prazo de citação de um devedor: média de 4 meses;

e) o volume médio de 30.000 processos é ajuizado em até quatro dias (ROTTA et al., 2013, p. ). 
Há claramente, portanto, um ganho com o intercâmbio de informações entre os atores de promoção da Justiça, o que justifica o estudo da interoperabilidade entre os sistemas dos atores envolvidos, corroborando com a hipótese "H3 - A interoperabilidade, da maneira que é utilizada, potencializa os benefícios do processo eletrônico".

\section{Avaliação de framework de Interoperabilidade}

Conforme definido na metodologia, foi buscado, na bibliografia, o modelo de avaliação de frameworks de interoperabilidade. O trabalho de Ray et al. (2010), além de apresentar modelo de avaliação, afirma que ele preenche a lacuna (falta de modelos de avaliação).

A definição dos aspectos considerados no desenvolvimento desta pesquisa baseia-se nos critérios adotados por Ray et al. (2010), quando de uma análise crítica de frameworks de interoperabilidade de governo. Esses autores definem três dimensões analisadas: contexto define o "por que"; conteúdo define "o que"; e processo define o "como" do modelo.

O domínio de contexto refere-se ao ambiente e a motivações da iniciativa de interoperabilidade, devendo ser avaliado através dos subdomínios "background" e "escopo", somado ao atendimento do conceito de interoperabilidade; o domínio de conteúdo refere-se às informações, ao modo como são intercambiados e aos padrões que possibilitam a interoperação -os subdomínios considerados são "política básica de interoperabilidade", "critério de seleção de padrões", "definição de padrões abertos" e "definição de tecnologias"; o domínio de processos está relacionado às definições de "ciclo de vida de padrões" e "política de gestão e complacência".

Para este trabalho, percebeu-se, como contribuição científica, a necessidade de estender os critérios de Ray et al. (2010), de modo a avaliar a observância do Modelo Nacional de Interoperabilidade quanto aos seus critérios avaliativos, mas observando o contexto de utilização judiciário e jurídico. É necessário um detalhamento de seus subdomínios, 
adequando à realidade em que o Modelo Nacional de Interoperabilidade se aplica. Cada critério é estendido e discutido.

\subsection{Background}

Ray et al. (2010) definem este aspecto como sendo aqueles que representam os aspectos legais e institucionais da iniciativa de interoperabilidade. Os autores deste estudo propõem-se a responder quanto à legalidade do modelo, avaliando se ele contempla os aspectos definidos na legislação e não se mostra contraditório às suas definições - serão considerados o Código de Processo Civil (1973) e a Lei do Processo Eletrônico (Lei 11.419/2006). Também será avaliado, de forma empírica, quanto ao cumprimento dos objetivos institucionais do Modelo, objetivando responder se ele é ou não cumprido.

Quando observadas as definições do Código do Processo Civil (1973), observamos que ele não traz definições em relação ao modo como as operações de troca de informações devam acontecer, e que o MNI respeita as definições legais da lei do processo eletrônico (Lei 11.419/2006) quanto aos padrões temporais de comunicação e troca de documentos (respeitando o Código do Processo Civil no que se relaciona a cômputo de prazos).

Com relação à sua definição e aos objetivos institucionais, o Modelo Nacional de Interoperabilidade foi criado "[...] com o intuito de proporcionar o intercâmbio de informações de processos judiciais e assemelhados entre tribunais e os diversos órgãos de administração da justiça no país". Observamos, segundo essa definição, que o MNI cumpre seu objetivo institucional, quando da possibilidade de intercâmbio de dados dos atores envolvidos em sua definição (STF, CNJ, STJ, CJF, TST, CSJT, AGU, PGR e o posteriormente integrado, que não se trata diretamente do judiciário, Conselho Nacional do Ministério Público CNMP, de competência independente), mas não contempla outros atores envolvidos, que fazem parte, inclusive, da administração pública - e atores envolvidos indiretamente com a justiça - como a polícia judiciária. 
Apesar de o Modelo Nacional de Interoperabilidade permitir o envio de um conjunto de dados não contemplados na definição inicial, através do uso de campos livres, cada tribunal poderia definir metadados próprios para receber os dados provenientes da Polícia Federal, Polícia Judiciária (normalmente competindo à Polícia Civil) ou outros órgãos de investigação, muitas vezes independentes da polícia - polícia científica ou institutos de perícia. Isso traz um ponto de indefinição e coloca em questão o tratamento do Modelo como um padrão a ser seguido pelos atores externos.

Ainda observando órgãos públicos, os advogados públicos (procuradores de estados ou municípios) recebem as citações, normalmente em nome do procurador geral. O Modelo é facilmente adaptável, mas não contempla, em seu cerne, a citação eletrônica como padrão utilizado nos serviços de comunicação (apesar de permitir o Cadastro Nacional de Pessoa Jurídica - CNPJ como identificador, possibilitando um ajuste fácil dessa operação), não trazendo clareza quanto ao responsável legal por receber a citação, por meio eletrônico. Deixa claro, porém, em sua documentação, o vínculo do procurador e a recepção das intimações pendentes.

Quando observados outros atores que não são da esfera pública (advogados privados), observa-se que não tiveram voz na discussão e que, apesar de proporcionarem uma biblioteca cliente desenvolvida em linguagem Java (linguagem de programação utilizada), gera dificuldade para a maioria dos desenvolvedores de soluções de software de baixo custo para escritórios de advocacia privada. Foi, porém, considerado nesta versão o intercâmbio de informações com aplicação "Escritório Digital”, em desenvolvimento pelo próprio CNJ, cujo foco foi possibilitar tal troca de informações e documentos dentro de seu escopo. Dessa forma, classificamos o atendimento às questões de background com ressalvas.

\subsection{Conceito de Interoperabilidade}

Ao afirmar que a interoperabilidade não é apenas a transferência de bits e bytes, mas uma tentativa de resolver o problema mais 
complexo de levar as pessoas e organizações para compartilhar informações (LANDSBERGEN; WOLKEN, 2001), observamos a necessidade de uma análise que avalie se as questões relacionadas às relações organizacionais e ambientais e se as interações estão de acordo com o propósito ou missão construídos. Ray et al. (2009) apontam que poderíamos ter diferentes conceitos sobre o que significa interoperabilidade e quais são suas dimensões. Para esses autores, qualquer iniciativa de interoperabilidade centrada em tecnologia pode contemplar apenas aspectos técnicos. Portanto, propõe-se que a categorização da European Interoperability Framework (IDABC, 2004 apud RAY et al., 2010) seja aplicada, classificando a iniciativa em:

1. interoperabilidade organizacional: preocupa-se com a definição de metas de negócios, modelagem de processos de negócios e colaboração das administrações que desejam trocar informações, podendo ter diferentes estruturas e processos internos;

2. interoperabilidade semântica: está relacionada com a compreensão do preciso significado das informações trocadas por qualquer aplicação não inicialmente desenvolvida para essa finalidade.

3. interoperabilidade técnica: está preocupada com as questões técnicas de ligação de sistemas de computador para compartilhar informações.

Neste trabalho, serão avaliadas as interações entre os atores, a partir das seguintes perguntas:

1. O Modelo Nacional de Interoperabilidade possibilita a troca de informações entre os atores envolvidos, com definição dos quesitos técnicos?

2. Os atores participaram das definições dos quesitos técnicos?

3. Os quesitos técnicos respondem a uma lógica compartilhada pelos atores internos e externos, de forma que ambos compreendam as informações contidas? 
4. Existe alguma ferramenta que possibilite entendimento de termos que tenham possíveis ambiguidades ou termos cuja utilização não seja compartilhada quanto ao seu uso?

5. Os serviços foram desenvolvidos de forma que foram preocupados com as atividades-chave dos atores externos envolvidos?

A partir das respostas a essas perguntas, será possível observar a classificação perante o subdomínio "conceito de interoperabilidade", visto que as perguntas (1) e (2), caso respondidas positivamente, respondem à classificação com uma iniciativa de interoperabilidade técnica; as perguntas (3) e (4) respondem à classificação como interoperabilidade semântica; e a pergunta (5) responde à interoperabilidade organizacional. Observa-se, porém, que, para que uma iniciativa contemple a interoperabilidade organizacional, ela deve contemplar os níveis semântico e técnico solidariamente. Uma iniciativa semântica deve contemplar, cumulativamente, o nível técnico, mas sem contemplar a interoperabilidade organizacional; caso uma iniciativa contemple apenas quesitos técnicos, ela é classificada como uma iniciativa de interoperabilidade técnica. Por sua vez, se os quesitos técnicos não são atendidos, não é possível considerá-la como uma verdadeira iniciativa de interoperabilidade.

Considerando o fato de que a interoperabilidade é uma forma de compartilhar informações entre sistemas e, sobretudo, entre organizações, foram respondidas as perguntas definidas. Obtivemos as seguintes respostas:

1. O Modelo Nacional de Interoperabilidade possibilita a troca de informações entre os atores envolvidos, com definição dos quesitos técnicos?

R: Os quesitos técnicos elencados pelo MNI permitem a troca de informações entre os atores envolvidos, mesmo que, para pequenos advogados privados ou públicos, isso represente um esforço complexo (quando comparado com os sistemas atuais). Também dificulta para 
advogados ou procuradores que estejam interessados em causas criminais, pois não há troca eletrônica de informações criminais, como dados da delegacia, dados de condenação ou da vida do apenado.

2. Os atores participaram das definições dos quesitos técnicos?

R: Considerando os objetivos institucionais, alguns atores participaram das definições dos quesitos técnicos. Os Tribunais de Justiça dos estados e do Distrito Federal não participaram de forma concreta.

3. Os quesitos técnicos respondem a uma lógica compartilhada pelos atores internos e externos, de forma que ambos compreendam as informações contidas?

R: Considerando os objetivos institucionais, todos os atores participaram das definições das lógicas para intercâmbio dos dados e documentos. Considerando os atores externos, não participantes, algumas lógicas não foram consideradas, como a citação de procuradores públicos e o intercâmbio de informações criminais com delegacias de polícia judiciária.

4. Existe alguma ferramenta que possibilite o entendimento de termos que tenham possíveis ambiguidades ou termos cuja utilização não seja compartilhada quanto ao seu uso?

R: Não existe definição de termos ou definições semânticas integrados ao MNI. Mesmo tabelas padronizadas (como tipo de documentos ou petições) não foram definidas.

5. Os serviços foram desenvolvidos preocupados com as atividades-chave dos atores externos envolvidos?

R: Não se observa preocupação com a integração dos processos internos dos atores. O documento não trata da integração do fluxo de trabalhos dos atores. Por exemplo, não há um padrão para informar que um processo está baixado ou que o tribunal de origem de um processo pode buscar as peças criadas em instância superior. 
Com base nas respostas encontradas, podemos afirmar que o Modelo Nacional de Interoperabilidade somente trata-se de uma iniciativa de interoperabilidade técnica.

\subsection{Escopo}

A definição de escopo, segundo Ray et al. (2010), refere-se ao foco de interação da iniciativa de interoperabilidade - podendo ser G2B (interação entre governo e empresas), G2C (governos e cidadãos) e G2G (entre órgãos do governo). Para este estudo, os autores buscaram entendimento dos papéis e avaliaram se o modelo pode atender outros órgãos (G2G, neste caso, representados por advogados públicos, autoridades policiais, Ministério Público e outros Tribunais), através de intercâmbio e troca das informações (neste caso, de informações processuais), cidadãos e empresas (G2C e G2B) que são atendidos através de seus representantes legais (advogados privados).

Considerando que o Modelo Nacional de Interoperabilidade atende os entes da administração pública, mas permite que pessoas físicas e jurídicas tenham seus interesses representados por advogados privados, intercambiando informações e documentos, podemos classificar o escopo do MNI como atendendo G2B (interação entre governo e empresas), G2C (governos e cidadãos) e G2G (entre órgãos do governo).

A necessidade de representação através de advogados públicos ou privados é dada pela legislação corrente (exceto juizados especiais), e tais obrigações não podem (ou devem) alterar a classificação quanto ao escopo.

\subsection{Política básica de interoperabilidade}

Refere-se à base política da interoperabilidade e fornece uma visão concisa da abordagem empreendida pelo modelo para atingir a interoperabilidade e um fundo para seleção de tecnologias apropriadas (RAY et al., 2010). 
No Brasil, através da Portaria SLTI/MP n 92, de 24 de dezembro de 2014, a política básica de interoperabilidade é definida através do framework e-PING (e-PING, 2014), e o CNJ define, com a Resolução nº 90, de 29 de setembro de 2009, a aplicação do e-Ping aos sistemas do Judiciário (Conselho Nacional de Justiça, 2009). O framework estabelece preocupações nas dimensões técnica (com subdimensões "alinhamento com a internet", "adoção de navegadores (browsers)" e "escalabilidade"), semântica ("desenvolvimento e manutenção de ontologias e outros recursos de organização da informação", "desenvolvimento e adoção de um padrão de modelagem de dados para governo", "desenvolvimento e adoção de uma política de disseminação de dados e informações") e organizacional ("simplificação administrativa", "promoção da colaboração entre organizações" e "garantia à privacidade de informação").

Avaliaremos, neste quesito, a adequação, em nível macro, das políticas adotadas pelo MNI em comparação às definições do e-PING.

Comparando as definições do MNI às definições do e-PING, aquelas se referem ao intercâmbio de informações, considerando somente os critérios técnicos, sobretudo preocupações de alinhamento à internet, adoção de padrões de intercâmbio baseados em WebService e documentos de padrão aberto, conforme padrões definidos pela W3C (World Wide Web Consortium).

Assim como no critério 4.2, não foram observadas as dimensões semânticas e organizacionais definidas no e-PING para as definições das políticas básicas.

\subsection{Critério de seleção de padrões}

Segundo Ray et al. (2010), os critérios básicos de seleção são geralmente parte integrante do documento de definição do framework de interoperabilidade. Os comuns são: seleção de padrões de interoperabilidade, escalabilidade, abertura, apoio ao mercado e segurança. 
Esses autores assumem que a definição do grupo de trabalho do e-PING estabelece os padrões definidos como sendo os padrões de mercado, seguindo as definições acadêmicas e estabelecidas por organismos como o W3C (World Wide Web Consortium). Dessa forma, os padrões estabelecidos no Modelo Nacional de Interoperabilidade serão comparados com os contidos na "Parte II - Especificações Técnicas dos componentes e-PING". A existência de especificações técnicas do $\mathrm{MNI}$ será avaliada, bem como a inexistência de algum padrão técnico estabelecido no e-PING. Assim, para este quesito, será avaliada somente a existência ou não de padrões selecionados, e se estão de acordo com as definições existentes.

Considerando as definições técnicas do e-PING, os autores deste estudo observam as cinco dimensões técnicas definidas, de forma macro:

1. interconexão: os critérios estabelecidos e tecnologias definidas cumprem os quesitos de interconexão definidos pelo framework e-PING, principalmente quanto às definições recomendadas do item "protocolo de troca de informações estruturadas em plataforma descentralizada e/ou distribuída";

2. segurança: os quesitos relacionados às assinaturas digitais, respeitando as definições de X.509 v3 (ICP-Brasil, SASL Simple Authentication and Security Layer, RFC 4422), definidas como recomendadas pelo e-PING, bem como a utilização de algoritmos de assinatura de XML (definidos como adotado). $\mathrm{O}$ envelopamento e a assinatura para garantir a confidencialidade de mensagens SOAP (WS-Security 1.1), como recomendado pelo e-PING, não são contemplados pelo MNI. As definições de carimbo de tempo, apesar de não obterem clareza do formato, a partir da documentação, parecem ser atendidas, considerando a existência de dados de protocolo que definam o tempo. $O$ modelo de transferência assíncrono pode (e deve) prevenir os ataques de Negação de Serviço Distribuídos (DDoS); 
3. meios de acesso: o MNI observa padrões de mercado definidos pelo e-PING, como as definições de arquivos intercambiáveis XML (recomendado pelo e-PING);

4. organização e intercâmbio de informações: considerando o intercâmbio de informações baseados em WebService, com padrões de intercâmbio de informações baseado em arquivos XML, observou-se que o intercâmbio é compreendido. Porém, a inexistência de vocabulários e ontologias que "permitam entendimento e controle do domínio das informações" (e-PING, 2014, p. 43) não é contemplada, tampouco auxiliam a definição do e-VOC (vocabulários de ontologias de governo eletrônico);

5. áreas de integração de governo eletrônico: o MNI não contempla catálogo de interoperabilidade, tampouco definições organizacionais que permitam uma maior definição de integração organizacional. Observa-se, porém, que os serviços são dispostos com a definição publicada, através de definição WSDL.

Alguns padrões definidos pelo e-PING são abarcados pelo MNI. No entanto, para que o MNI seja considerado adequado quanto ao e-PING, são necessárias algumas adequações.

\subsection{Definição de padrões abertos}

Neste aspecto, os autores assumem que as definições referentes a padrões abertos do e-PING e definidos pela W3C (World Wide Web Consortium) devem ser respeitados no Modelo Nacional de Interoperabilidade. Como a definição de "padrões abertos" é muito ambígua, podendo observar se o padrão é inteligível ou não, proprietário ou não proprietário (padrão de mercado, sem dono e sem pagamento de royalty), devemos, para este trabalho, estabelecer uma definição para padrões abertos. Assim como utilizado no e-PING, para quesito relacionado às definições de padrões abertos, este estudo considerará como ideais os padrões classificados como "royalty-free", ou seja, 
inteligíveis por computador sem que necessitem de licenças pagas. Também serão considerados aspectos como documentação do padrão, possibilidade de redistribuição, reuso sem royalty, utilização de padrões internacionais (neste caso, se seguem definições da W3C), se podem ser utilizados para outros sistemas de apoio a decisão (que não de origem governamental), seguindo as subdimensões definidas em Ray et al. (2010).

Levando em consideração o conceito de "royalty-free", observase que os padrões definidos pelo MNI, sobretudo uso de WebServices com a transferência de documentos XML assinados digitalmente, representam uso de padrões abertos.

Observa-se que o MNI não apresenta padrões para reutilização das informações, sobretudo respostas quanto possíveis estatísticas geradas pelo Judiciário, ou seja, não contempla esse tipo de transmissão de dados - focando somente em dados diretamente relacionados com ações diretas nos processos pelos órgãos envolvidos ou representantes legais.

\subsection{Definição de tecnologias}

Para Ray et al. (2010), um framework de interoperabilidade governamental, para ser verdadeiramente interoperável sob aspectos técnicos, deve conter especificações que objetivam abranger todas as camadas da arquitetura e-governo propostas no estudo. Deve considerar critérios de interconexão (INT) cujos padrões definidos pela W3C são de mensagens sobre protocolo hipertexto (HTTP, IPV4. IPV6, LDAP, FTP, SMTP, POP, SOAP, WebServices Description Language - WSDL); intercâmbio de dados (DTE) com tecnologias como Extensible Markup Language (XML), Extensible Style sheet Language Transformations (XSLT), Web Ontology Language (OWL), Entity Relationship Diagram and XML Schema Definition (XSD); gestão de conteúdo (COM), possibilitando acesso e intercâmbio diretamente, apontando tecnologias como Resource Description Framework (RDF), ou a definição de metadados que possibilitem acessar o conteúdo 
sem conhecer sua modelagem; Integração de Aplicações (API) (ou middleware), possibilitando que aplicações externas sejam integradas às governamentais; apresentação dos serviços e acesso (PRS), apontando possibilidades como UNICODE, UTF-8/16, HTML, XHTML, Cascading Style Sheets, XForms, WML, Ecma Script/Javascript, JPEG, GIF, PNG, TIFF, MPEG, RealAudio/RealVideo, Text File (.txt), PDF; e segurança (SEC), citando que alguns frameworks de interoperabilidade governamental separam essas camadas de segurança das tecnologias (inclusive aponta o e-PING entre elas), apontando tecnologias como IPsec, SSL, Transport Layer Security (TLS), International Standard for Identity Certificates. (X.509), Secure Hash Algorithm (SHA), DES, RSA, DSA, Secure/Multipurpose Internet Mail Extensions with Encrypted Security Service (S/MIME ESS), Security Assertions Markup Language (SAML) e Compliance with WS-I Basic Profile version 1.1/1.2.

Os autores deste estudo avaliam a existência dessas preocupações, dessas cinco subdimensões, bem como comparam com os padrões de mercados definidos no e-PING e W3C. Com base nas definições de tecnologias, é necessário observar todas as camadas arquiteturais para a definição do framework:

1. interconexão (INT): os critérios estabelecidos e tecnologias definidas cumprem os quesitos de interconexão definidos pelo framework e-PING, bem como as definidas pelo W3C, através de padrões de utilização de padrões definidos pela W3C (SOAP, WebServices Description Language - WSDL);

2. intercâmbio de dados (DTE): a utilização de arquivos XML e definição de validações através de XSD (XML Schema Definition) cumprem requisitos do e-PING e W3C;

3. gestão de conteúdo (COM): os metadados são definidos diretamente na descrição do Web-Service (WSDL), não contemplando definições em Resource Description Framework (RDF), Web Ontology Language (OWL) ou possibilidade de definições de metadados através de anotações semânticas; 
4. integração de aplicações (API): as definições do MNI permitem a troca de informações, mas não permite a integração direta de aplicações, de forma que as aplicações funcionem em conjunto;

5. segurança (SEC): os critérios de segurança quanto à confiabilidade do documento é gerada através de sua assinatura digital (padrão X.509 - ICP-Brasil), conferindo também integridade ao documento.

Tecnologias das camadas de integração (INT), intercâmbio (DTE) e segurança (SEC) são contemplados no MNI. Porém, as camadas de gestão de conteúdo (COM) e integração de aplicações (API) não recebem iniciativas ou preocupações.

\subsection{Ciclo de Vida de Padrões}

O ciclo de vida de padrões deve determinar os padrões, considerando as mudanças de requisitos, classificando-os quanto à sua utilização atual, futura ou considerada obsoleta, além de definir o seu ciclo de vida e os critérios para tais definições (RAY et al., 2010).

Assim, os autores observarão, na documentação do Modelo Nacional de interoperabilidade, a existência da gestão do ciclo de vida de padrões.

Considerando a documentação disponibilizada pelo $\mathrm{MNI}$, os padrões definidos não recebem classificação quanto ao ciclo de vida, não são definidos critérios claros quanto à retirada de um padrão (definição como obsoleto), tampouco é elencada uma lista de padrões estudados que podem, no futuro, ser absorvidos pelo Modelo.

Apesar de apresentar uma definição clara de padrões adotados, a falta dessas informações ou de comunicações com desenvolvedores de solução gera uma incerteza quanto às definições de próximas versões, principalmente considerando atores externos (por exemplo, advogados privados). 
A definição de padrões estudados, adotados, recomendados e obsoletos, como definidos na documentação do e-PING (e-PING, 2014), poderia diminuir tais incertezas e passar mais segurança aos desenvolvedores de aplicações para atores externos e não participantes das definições do MNI.

\subsection{Política de gestão e conformidade}

Com relação à política de gestão e conformidade, Ray et al. (2010) apontam possíveis processos, como a construção colaborativa, o uso de audiências públicas e a participação acadêmica para definição de padrões, pois com ela é possível gerir melhor a política de conformidade. A existência da portaria que instituiu o e-PING, define, através de política institucionalizada, que os padrões devem ser estar em conformidade ao e-PING.

Nesse ponto, os autores avaliarão os pontos do e-PING que não são contemplados no $\mathrm{MNI}$, ou aqueles que são divergentes, apontando as não conformidades quanto ao definido legalmente.

Quando considerada a política de gestão do Modelo, alguns atores participam ativamente no desenvolvimento de padronizações, sobretudo atores que representam Tribunais e órgãos de administração da justiça no país. A não participação da sociedade e de atores externos apresenta um risco ao modelo.

Algumas definições organizacionais não foram realizadas pelo MNI e algumas transferências podem ser aceitas perante o MNI, apesar de apresentarem inconsistências perante sua conformidade. Os exemplos mais claros são a indefinição de tipo de documento e a não utilização de tabelas padronizadas de códigos, como de atores, municípios etc., em desacordo com as definições das tabelas unificadas de classe, assunto e movimentação, definidas pelo $\mathrm{CNJ}$, que já preveem definições para estas - as definições são, portanto, existentes, mas insuficientes.

Dessa forma, observa-se que os critérios para definição de padrões, a gestão e o ciclo de vida, bem como a utilização de grupos 
de estudos específicos aplicados nas definições do e-PING não são aplicados para as definições do Modelo Nacional de Interoperabilidade.

\section{Considerações sobre o Modelo Nacional de Interoperabilidade}

A partir da avaliação realizada, considerando o padrão de avaliação encontrado na literatura, observa-se um grande número de critérios cujo resultado contempla os critérios de avaliação, total ou parcialmente.

Aponta-se como principal ponto positivo o fato de atender um escopo que abrange um grande número de atores e, principalmente, a disponibilização de serviços que contemplam uma parcela grande das operações de intercâmbio de dados e informações, sobretudo quando se refere a operações entre Tribunais ou entre Tribunais e órgãos públicos, contemplando, também, grande parte das operações que envolvem Tribunais e advogados (públicos e privados).

Aponta-se, ainda, que o Modelo Nacional de Interoperabilidade observa os critérios da lei do processo eletrônico (Lei 11.419/2006) e respeita a legislação processual (sobretudo do código de processo civil), o que confere um ganho performático, quando comparado ao modo físico de processos ou troca de informações, sem contradição às suas regras.

Apesar de grandes benefícios encontrados e potenciais, os autores deste estudo apontam algumas críticas ao Modelo, as quais podem refletir-se em melhorias para as próximas versões:

1. a não observância de atores externos, que poderia ser feita através de sua representação, estabelecendo a contemplação de serviços adequados a todos os atores envolvidos e usuários do modelo;

2. quanto ao escopo, o modelo só contempla comunicação com abertura e protocolação de novos processos, não possibilitando a transferência de informações entre órgãos e Tribunais que não contemplem a abertura de processos. Aponta-se como 
exemplo uma condenação criminal em Tribunais de Justiça ou Justiça Federal que impute perda de direitos políticos e deve ser comunicada ao Tribunal Regional Eleitoral;

3. quanto à segurança da informação, aponta-se que o envelope XML não é assinado pelo autor ou entidade que envia, sendo assinados somente os documentos. Dessa forma, não é dada garantia de origem dos documentos. Aponta-se como exemplo uma delegacia que manda inquérito policial cujos documentos são assinados pelo delegado, mas sem qualquer assinatura do envelope pela instituição, não existindo nenhuma garantia de que o delegado pertence àquela delegacia. Da mesma forma, os padrões de segurança e acesso de sistemas de informações de um Ministério Público devem ser replicados nos sistemas que recebem a informação, para garantir a origem (considerando somente o CPF);

4. a definição de metadados do modelo é genérica, deixando muitas informações para serem inseridas na variável "parâmetro", de tipo aberto, que depende de acordo semântico entre as duas partes. O problema é que, por exemplo, o acordo entre sistema prisional e um tribunal pode não ser igual à implementação feita por outro tribunal, que também recebe informações. Portanto, sistema que intercambia investigações da polícia judiciária a um Tribunal de Justiça Estadual, envolvendo ações relacionadas a outros estados (e consequente envio de informações a outro tribunal), pode não funcionar se o segundo tribunal define utilizações diferentes para a variável "parâmetro" quanto ao envio de informações do inquérito;

5. quando considerados padrões para conformidade e aceite de dados enviados, muitos campos não aplicam padrões já consolidados ou que mereçam definições. Apontam-se como exemplo as informações de nome do município que são enviadas através de um campo texto, em vez de usar código IBGE, como outros serviços de governo eletrônico, 
sobretudo estabelecidos por órgãos do Poder Executivo. Da mesma forma, algumas informações intercambiadas podem gerar problemas como tipos de peças e documentos que merecem padronização, a exemplo das definições de tabelas unificadas pelo CNJ, como são os casos de assuntos, classes e movimentações. Soma-se à indefinição o processo de repúdio quando do não reconhecimento das informações enviadas: não existe serviço para consulta dos valores aceitos, só respondendo à lista de valores possíveis em caso de falha. Exemplo disso é percebido na exigência da definição de competência ao enviar uma inicial. O Tribunal avalia e devolve a lista de competências somente em caso de falha.

6. as definições de interoperabilidade semântica e interoperabilidade organizacionais, apesar de trabalhosas, poderiam promover uma evolução do Modelo Nacional de Interoperabilidade;

7. o padrão de comunicação entre Tribunais para envio de iniciais requer uma série de comunicações em sequencia e de forma bidirecional, provocando processamento desnecessário, como o envio do número do protocolo ao tribunal de origem duas ou mais vezes. Tais definições deveriam sofrer melhorias;

8. O Modelo Nacional de Interoperabilidade apresenta algumas lacunas de definição, possibilitando que os Tribunais façam definições específicas - ainda que sem contradição ao modelo. Tais "liberdades" podem alterar seu comportamento e provocar a necessidade de múltiplas implementações para intercâmbio em Tribunais distintos, quebrando o conceito de padronização;

9. a gestão do ciclo de vida dos padrões deve considerar estudos acadêmicos, padrões de mercado e passar segurança aos desenvolvedores de soluções de software;

10. a apresentação de Interfaces de Aplicação (API) poderia fornecer interoperabilidade entre os sistemas que implementem 
- Modelo Nacional de Interoperabilidade, de forma a possibilitar o desenvolvimento de aplicações por terceiros (empresas de software), sobretudo daqueles módulos que os sistemas padronizados não atenderiam.

Com base na comparação do Modelo Nacional de Interoperabilidade, como os critérios críticos apontados por Ray et al. (2010), podemos observar o atendimento de um grande número de critérios, e, quando não, este estudo aponta críticas que podem ser interpretadas como sugestões. Dessa forma, a hipótese "H4 - O Modelo Nacional de Interoperabilidade contempla os requisitos definidos pela literatura, em caso de avaliação segundo critérios por ela definidos" é parcialmente confirmada.

\section{Conclusões}

O Modelo Nacional de Interoperabilidade, criado e mantido pelo Conselho Nacional de Justiça, pode e deve contribuir para novas integrações de sistemas de atores envolvidos e o Poder Judiciário.

A pesquisa bibliográfica apontou os benefícios do processo eletrônico, a existência de framework de interoperabilidade para sistemas a serem desenvolvidos no Brasil (e-Ping), bem como o modelo de interoperabilidade, com definições formais para interoperabilidade no Judiciário - o Modelo Nacional de Interoperabilidade. Apesar de, na literatura, não ter sido encontrado material algum apontando benefícios quantitativos do MNI, a interoperabilidade, mesmo que o Tribunal tenha utilizado modelo próprio de interoperabilidade, mostrou benefícios claros, com incremento de desempenho com a integração. Dessa forma, as hipóteses iniciais foram confirmadas, o que levou à continuidade da pesquisa quanto à avaliação do Modelo.

Em levantamento bibliográfico, foi definido um modelo de avaliação e sua adaptação para a realidade do Judiciário brasileiro. Com a aplicação da avaliação, foi observado o atendimento de um grande número de critérios, total ou parcialmente. O processo de avaliação possibilitou a 
observação de incremento dos benefícios do processo judicial eletrônico com um intercâmbio digital de documentos e comunicações. Ainda com base nos critérios de avaliação, foram apontados critérios não cumpridos pelo modelo e, a partir deles, os autores sugeriram melhorias. Dessa forma, a hipótese de que o MNI contempla os requisitos definidos pela literatura é parcialmente confirmada. O presente artigo apresenta, como maior contribuição, a avaliação do Modelo de Interoperabilidade de Dados do poder judicial brasileiro através de modelo de avaliação, estabelecendo vantagens para o uso do modelo, bem como propostas de melhoria.

\section{Referências}

APRESENTAÇÃO. Revista Gestão e Inovação, Salvador, ano 1, n. 1, p. 1, jun. 2005. Disponível em: <www.saeb.ba.gov.br/downloads/ gestaoinovacao_n1.pdf>. Acesso em: 20 fev. 2014.

BOTELHO, F. N. O processo eletrônico escrutinado. Rio de Janeiro: IAB, 2007. Disponível em: <http://www.iabnacional.org.br/IMG/pdf/doc992.pdf>. Acesso em: 27 out. 2013.

BRASIL. Constituição (1988). Constituição da República Federativa do Brasil. Brasília: Senado Federal, 1988.

BRASIL. Lei $\mathbf{n}^{\circ}$ 11.419, de 19 de dezembro de 2006. Dispõe sobre a informatização do processo judicial; altera a Lei no 5.869, de 11 de janeiro de 1973 - Código de Processo Civil; e dá outras providências. Disponível em: <http://www.planalto.gov.br/ccivil_03/_ato20042006/2006/lei/l11419.htm> Acesso em: 25 jan. 2014.

BRASIL. Conselho Nacional de Justiça. Sobre o Conselho Nacional de Justiça. Brasilia: CNJ, [20--]. Disponível em: <http://www.cnj.jus.br/ sobre-o-cnj>. Acesso em: 25 jan. 2014.

Modelo Nacional de Interoperabilidade. Brasilia: CNJ, 2007.

Disponível em: <http://www.cnj.jus.br/programas-de-a-a-z/eficienciamodernizacao-e-transparencia/comite-nacional-da-tecnologia-da- 
informacao-e-comunicacao-do-poder-judiciario/modelo-nacional-deinteroperabilidade>. Acesso em: 20 fev. 2014.

Resolução n. 4, de 16 de agosto de 2005. Cria o Sistema de Estatística do Poder Judiciário e dá outras providencias. Disponível em: <http://www.cnj.jus.br/images/programas/justica-em-numeros/atosnormativos/resolucao-n4-16-agosto-2005.pdf>. Acesso em: 25 jan. 2014.

Resolução n. 90, de 29 de setembro de 2009. Dispõe sobre os requisitos de nivelamento de tecnologia da informação no âmbito do Poder Judiciário. Disponível em: <http://www.cnj.jus.br/images/ programas/justica-em-numeros/atos-normativos/resolucao-n4-16agosto-2005.pdf>. Acesso em: 20 fev. 2014.

Modelo interoperabilidade de dados do poder judiciário. Versão 2.2.2. Brasília: Conselho Nacional de Justiça, 2014.

BRASIL. Governo Eletrônico. Documento de Referência da e-Ping. 2014. Disponível em: <http://www.governoeletronico.gov.br/biblioteca/ arquivos/documento-da-e-ping-versao-2014/>. Acesso em: 24 jun. 2014.

DOWNEY, H.; IRELAND, R. D. Quantitative versus qualitative: the case of environmental assessment int organizational. Administrative Science Quarterly, Nova Iorque, v. 24, n. 4, p. 630-637, 1979.

GODOY, A. S. Introdução à pesquisa qualitativa e suas possibilidades. Revista de Administração de Empresas, São Paulo, v. 35, n. 2, p. 57-63, 1995.

BRASIL. Ministério do Planejamento, Orçamento e Gestão. Padrões de interoperabilidade de governo eletrônico: documento de referência. Brasília, 2015. Disponível em: <http:// www.governoeletronico.gov.br/documentos-e-arquivos/e-PING_ v2016_26022016.pdf>. Acesso em: 22. ago. 2016

FLAK, L. S. et al. What is the value of eGovernment: and how can we actually realize it? Transforming government: People, Process and Policy, Bingley, v. 3, n. 3, p. 220-6, 2009. Disponível em: <http://www. 
emeraldinsight.com/doi/abs/10.1108/17506160910979333>. Acesso: 03 jun. 2015.

HININGS, C. R. The changing nature of professional organizations. In: ACKROYD, S.; BATT, R.; THOMPSON, P.; TOLBERT, P. S. (Dir.). The Oxford handbook of work and organization. Oxford: Oxford University Press, 1995. p. 405-424.

INTERNATIONAL ORGANIZATION FOR STANDARDIZATION ISO. ISO/IEC 2382-1:1993 Information technology - Vocabulary - Part 1:Fundamental terms. Geneva,1993.

KRAMMES, A. G. Aplicação de workflow em processos judiciais eletrônicos. 2008. 124 f. Dissertação (Mestrado Programa em Engenharia e Gestão do Conhecimento) - Universidade Federal de Santa Catarina, Florianópolis, 2008.

LALLANA, E. C. E-government interoperability: e-primers for the information economy, society and polity, United Nations development programme, regional centre in Bangkok. Bangkok, 2008. Disponível em: <www.apdip.net/publications/iespprimers/eprimer-gif.pdf>. Acesso em: 20 ago. 2014.

LEAL, A. C. C. O processo judicial telemático: considerações propedêuticas acerca de sua definição e denominação. Jus Navigandi, Teresina, ano 11, n. 1268, dez. 2006. Disponível em: <http://jus.com.br/revista/texto/9296>. Acesso em: 28 out. 2013.

LEAL, A. C. C. O princípio da publicidade no processo judicial telemático e suas repercussões na legitimidade democrática do poder judiciário. 2009. Disponível em: <http://ojs.idp.edu.br/index. php/observatorio/article/viewFile/250/207>. Acesso em: 28 out. 2013.

LIMA, G. M. e-Processo: uma verdadeira revolução procedimental. 2002. Disponível em: <http://jus.com.br/revista/texto/3924>. Acesso em: 28 out. 2012.

MACIEL, A. F. Considerações sobre as causas do emperramento do Judiciário. BDJur, Brasília, 2000. Disponível em: <http://bdjur.stj.gov. br/dspace/handle/2011/24688>. Acesso em: 28 out. 2013. 
MADALENA, P. Processo judicial virtual. 2007. Disponível em: <http://unieducar.org.br/artigos/Processo\%20Judicial\%20Virtual\%20 pdf.pdf>. Acesso em: 27 out. 2013.

Advogando com peticionamento e processo eletrônicos. Revista CEJ, Brasília, ano XVI, n. 56, p. 117-127, jan./abr. 2012. Disponível em: <http://www2.cjf.jus.br/ojs2/index.php/cej/article/ view/1609/1554>. Acesso em: 27 out. 2013.

BRASIL. Conselho Nacional de Justiça. Modelo de interoperabilidade de dados do Poder Judiciário e órgãos de administração da Justiça versão 2.2.2. Brasília: CNJ, 2014. Disponível em: <http:// www.cnj.jus.br/tecnologia-da-informacao/comite-nacional-datecnologia-da-informacao-e-comunicacao-do-poder-judiciario/modelonacional-de-interoperabilidade/arquivos-do-modelo-nacional-deinteroperabilidade>. Acesso em: 20 jan. 2015.

BRASIL. Governo Eletrônico. O que é Interoperabilidade? [201?]. Disponível em: <http://www.governoeletronico.gov.br/acoes-e-projetos/ e-ping-padroes-de-interoperabilidade/o-que-e-interoperabilidade>. Acesso: 20 fev. 2014.

NEVES, J. L. Pesquisa qualitativa: características. Caderno de Pesquisas em Administração, São Paulo, v. 1. n. 3, 1996. Disponível em: <http://www.unisc.br/portal/upload/com_arquivo/pesquisa_ qualitativa_caracteristicas_usos_e_possibilidades.pdf>. Acesso em: 20 jan. 2015.

\section{OLIVIERI, R. C. Autos eletrônicos na justiça federal da $\mathbf{2 a}$}

região: a contribuição do processo eletrônico na redução do tempo de tramitação dos processos, 2010. 90 f. Dissertação (Mestrado Profissional em Poder Judiciário). Escola de Direito do Rio de Janeiro, Fundação Getúlio Vargas, Rio de Janeiro, 2010.

RAY, D. et al. Interoperability and constituents of interoperable systems in public sector. In: WEERAKKODY, V.; JANSSEN, M.; DWIVEDI, Y. K. (Eds.). Handbook of research on ICT: enabled transformational government: a global perspective. Hershey: IGI Global, 2009. p. 175195. 
RAY, D. et al. A critical survey of selected government interoperability frameworks. Transforming government: People, Process and Policy, Hershey, v. 5 n. 2, p. 114-142, 2011.

RIBEIRO, A. P. O judiciário como poder político no século XXI. Estudos Avançados, São Paulo, v.14, n.38, p. 291-306, 2000. Disponível em: < http://www.scielo.br/pdf/ea/v14n38/v14n38a17.pdf>. Acesso em: 18 set. 2013.

RIFKYN, J. O sonho europeu. São Paulo: Makron Books do Brasil, 2005.

ROVER, A. J. Definindo o termo processo eletrônico. 2008.

Disponível em: <http://www.infojur.ufsc.br/aires/arquivos/ conceitoprocessoeletronico.pdf>. Acesso em: 11 ago. 2013.

ROVER, A. J. Introdução ao governo eletrônico. In: ROVER, A. J. (Org.). Governo eletrônico e inclusão digital. Florianópolis: Fundação Boiteux, 2009. p. 17-37.

ROTTA, M. J. R. et al. Aceleração processual e o processo judicial digital: um estudo comparativo de tempos de tramitação em Tribunais de Justiça. Revista Democracia Digital e Governo Eletrônico, Florianópolis, v. 1, n. 8, p. 125-154, 2013.

; ROVER, A. J.; SILVA, P. Justiça estadual brasileira: aderência às práticas de Governança de Tecnologia da Informação. Revista Democracia Digital e Governo Eletrônico, Florianópolis, v. 2, n. 5, p. 173-192, 2011. Disponível em: <http://www.buscalegis.ufsc.br/revistas/ index.php/observatoriodoegov/article/view/34113/33068>. Acesso em: 12 out. 2013.

SILVA, E. et al. Visão sistêmica na interoperabilidade dos sistemas para segurança pública: estudo do caso de Santa Catarina. In: CONFERÊNCIA IADIS IBERO-AMERICANA WWW/INTERNET 2008, Lisboa. Anais... Lisboa, Portugal: IADIS Press, 2008. p. 472-476.

SILVA, L. P. Princípios fundamentais da administração judiciária. Jus Navigandi, Teresina, ano 10, n. 886, dez. 2005. Disponível em: <http:// jus.com.br/artigos/7666>. Acesso em: 10 jan. 2014. 
SILVA, S. W. A. Processo eletrônico. O impacto da Lei n. 11.419/2006 na mitigação da morosidade processual na prestação jurisdicional brasileira. Jus Navigandi, Teresina, ano 15, n. 2553, jun. 2010. Disponível em: <http://jus.com.br/revista/texto/15112>. Acesso em: 27 out. 2013.

SOUZA, A. C.; FIALHO, F. A. P.; OTANI, N. TCC: métodos e técnicas. Florianópolis: Visual Books, 2007.

Recebido em: 28/10/2015

Aprovado em: 21/12/2015 